\title{
Het effect van omgevingsverandering op het lunchwandelgedrag van werknemers
}

\author{
M. Simons, ${ }^{1}$ A. de Boer, ${ }^{1}$ M. Jans, ${ }^{1}$ I.J.M. Hendriksen ${ }^{1,2}$
}

\begin{abstract}
Aanleiding: Een bedrijf verhuist van een pand met een primitieve kantine en een aangename wandelomgeving naar een nieuw gebouw met een modern bedrijfsrestaurant en een minder aantrekkelijke wandelomgeving. In deze studie is het effect van deze omgevingsveranderingen op de mate waarin gewandeld wordt tijdens de lunch geobserveerd. Methoden: Het lunchwandelgedrag en mogelijke belemmerende factoren voor lunchwandelen werden achttien weken voor de verhuizing en één jaar later via een online vragenlijst geïnventariseerd. Om het lunchwandelgedrag tijdens het onderzoeksjaar te monitoren zijn periodieke e-mails naar de deelnemers verstuurd met enkele korte vragen over het lunchwandelen. Resultaten: 123 deelnemers (55\% van de werknemers) vulden beide vragenlijsten in. Bij aanvang van de studie wandelde $64 \%$ minimaal één keer per week en $49 \%$ minimaal vier keer per week tijdens de lunch. Na een jaar wandelde nog slechts $31 \%$ minimaal één keer per week en 9\% minimaal vier keer per week. De gemiddelde duur van een lunchwandeling veranderde niet significant. Bijna driekwart van de deelnemers (73\%) gaf aan dat zowel het nieuwe bedrijfsrestaurant als de veranderde bedrijfsomgeving de oorzaak waren van het minder frequent lunchwandelen. Conclusie: De gewoonte om veel te wandelen tijdens de lunch is niet opgewassen tegen ongunstige omgevingsveranderingen. Zowel de inrichting van het bedrijf met een modern restaurant als een minder gunstige bedrijfsomgeving kunnen in belangrijke mate het lunchwandelgedrag bepalen.
\end{abstract}

Trefwoorden: fysieke omgeving, bewegen, bedrijfsrestaurant, werksetting

\section{INLEIDING}

Verschillende studies hebben aangetoond dat regelmatig bewegen sterk samenhangt met een betere fysieke en psychische gezondheid en een verminderd risico op diverse belangrijke doodsoorzaken en chronische aandoeningen. ${ }^{1-3}$ Ondanks de vele voordelen van bewegen zijn veel mensen te weinig actief. Van de werkende bevolking in Nederland voldoet 30\% niet aan de beweegnorm. ${ }^{4}$ Deze norm raadt alle gezonde volwassenen in de leeftijd 18 tot 65 jaar aan om minstens een half uur op minimaal vijf dagen per week minimaal matig intensief lichamelijk actief te zijn, of om tenminste drie keer per week gedurende minimaal 20 minuten intensief te bewegen. ${ }^{5}$ Vooral kantoormedewerkers die alles binnen handbereik hebben bewegen te weinig in hun dagelijkse leven. ${ }^{6,7}$

Wandelen is een uitstekende manier om het dagelijkse zitgedrag op het werk te doorbreken. Het is een laagdrempelige vorm van bewegen die voor bijna iedereen toegankelijk is. Regelmatig wandelen kan eenvoudig in de dagelijkse routine worden opgenomen, is goedkoop en de

\footnotetext{
${ }^{1}$ TNO Kwaliteit van Leven, Leiden

2 Body@Work, Onderzoekscentrum Bewegen, Arbeid en Gezondheid, TNO-VUmc, Amsterdam
}

kans op blessures is klein. ${ }^{8,9}$ Wandelen is tevens de meest gewaardeerde vorm van lichamelijke activiteit in de Europese Unie. ${ }^{10}$

Wandelen tijdens de lunchpauze is heel gebruikelijk in Nederland. Resultaten van een landelijke enquête onder werknemers laten zien dat 20 tot $30 \%$ van de werknemers wandelt tijdens de lunch. ${ }^{11}$ Van de werknemers met een zittend beroep gaf $35 \%$ aan wel te willen bewegen tijdens de lunchpauze als collega's met hen mee zouden gaan of als de werkgever dit zou stimuleren. De meerderheid van de werknemers (70\%) is echter niet fysiek actief tijdens de lunchpauze. ${ }^{11,12}$

De afgelopen jaren is het aantal studies naar de invloed van de fysieke omgeving op het wandelgedrag toegenomen. Er lijken aanwijzingen te zijn voor een relatie tussen het wandelgedrag en de esthetiek van de omgeving, de geschiktheid en toegankelijkheid van wandelpaden en parken en de hoeveelheid verkeer in de omgeving. ${ }^{13-16}$

Een unieke gelegenheid om de relatie tussen omgeving en wandelgedrag te onderzoeken deed zich voor toen een bedrijf, waar veel werd gewandeld tijdens de lunch, ging verhuizen. Men verhuisde van een locatie in het centrum van het dorp, met mooie wandelpaden en veel winkels in de buurt en een zeer primitieve kantine, naar een bui- 
tenwijk van hetzelfde dorp, met een minder aantrekkelijke wandelomgeving en een modern bedrijfsrestaurant in het pand. Het doel van deze observationele studie is om na te gaan wat het effect van een veranderde fysieke omgeving is op het aantal werknemers dat lunchwandelt, en op de frequentie en de duur van het lunchwandelen.

\section{METHODE}

\section{Deelnemers en studie opzet}

De onderzoekspopulatie bestond uit 223 werknemers werkzaam bij een marktonderzoeksbureau in een klein dorp in Nederland. Alle werknemers werden benaderd voor deelname aan het onderzoek, echter alleen degenen die gedurende de volledige duur van de studie bij het bedrijf werkzaam waren, werden meegenomen in de analyses. Bijna alle werknemers hadden een zittend beroep.

Door de verhuizing veranderde zowel de fysieke omgeving van het bedrijf als de faciliteiten in het bedrijfspand zelf. Om de effecten van deze veranderde omgeving te onderzoeken werd aan de werknemers gevraagd aan het begin en eind van de studie een online vragenlijst in te vullen en gedurende het onderzoeksjaar regelmatig e-mails te beantwoorden met vragen over het lunchwandelgedrag.

\section{Metingen}

De vragenlijsten werden 18 weken voor (juni 2006) en 34 weken na (juni 2007) de verhuizing uitgezet en de onderwerpen die aan bod kwamen waren de frequentie en duur van een lunchpauze, activiteiten die gedaan werden tijdens de lunchpauze inclusief het wandelgedrag, de belangrijkste redenen voor het (niet) wandelen, stimulerende omstandigheden, de aantrekkelijkheid van de fysieke omgeving, de houding van collega's ten aanzien van lunchwandelen en algemene kenmerken (o.m. naam, geslacht, functie, gezondheid en beweeggedrag). Alle antwoorden op frequentievragen werden gerelateerd aan het aantal dagen per week dat de werknemer werkzaam was en omgerekend naar een vijfdaagse werkweek.

Twee weken na het verzenden van beide vragenlijsten en ongeveer elke acht weken gedurende het onderzoeksjaar werden er drie e-mails in drie opeenvolgende weken naar deelnemers verstuurd. Deze e-mails bevatten vier vragen over het lunchwandelgedrag van de voorafgaande week. De tweede vragenlijst werd alleen gestuurd naar de werknemers die de eerste vragenlijst hadden ingevuld en bevatte dezelfde vragen als de eerste vragenlijst, aangevuld met een aantal vragen over de situatie na de verhuizing.

\section{Bedrijfssituatie}

Het werkklimaat in het bedrijf kan beschreven worden als veeleisend als gevolg van een hoge werkdruk. Er zijn veel jonge mensen met een groot verantwoordelijkheidsgevoel werkzaam. Werknemers mogen zelf bepalen wanneer ze lunchpauze nemen en het is toegestaan een lunchpauze van langer dan 30 minuten te nemen wanneer ze deze tijd op een ander moment inhalen. Gezondheid is een aandachtspunt in het bedrijf en sportevenementen worden gesponsord. Sinds de verhuizing krijgen werknemers korting bij een fitnessclub in de buurt en wordt er aandacht besteed aan gezonde voeding in het bedrijfsrestaurant.

\section{Statistische analyses}

Om het verschil tussen voor- en nameting wat betreft frequentie en duur van de lunchpauze, frequentie van het lunchwandelen en beweeggedrag te toetsen werd een gepaarde T-Toets gebruikt. De McNemar (-Bowker) test werd toegepast om de verschillen te bestuderen in het aantal lunchwandelende werknemers en om de resultaten van vragen over activiteiten gedurende de lunchpauze, gezondheid, houding van collega's en direct leidinggevenden en de aantrekkelijkheid van de bedrijfsomgeving te toetsen. Om het verschil in wandelduur te bekijken werd de Wilcoxon Signed Ranks Test gebruikt. Er werd uitgegaan van een significantieniveau van $p<0,05$.

\section{RESULTATEN}

\section{Deelnemers}

Van de 161 werknemers (72\%) die de eerste vragenlijst invulden werden drie personen geëxcludeerd, omdat ze een tijdelijk contract hadden. De achtergrondkenmerken van de 158 geïncludeerde deelnemers zijn weergegeven in tabel 1 . De meeste deelnemers (73\%) reageerden regelmatig (minimaal 13 keer) op de in totaal achttien periodieke e-mails. De tweede vragenlijst werd door 123 werknemers ingevuld (figuur 1). De uitvallers verschilden niet significant wat betreft geslacht, leeftijd, werkuren, werkdagen, lunchpauze frequentie en lunchwandelfrequentie (zoals gemeten bij de voormeting) met de werknemers die beide vragenlijsten hebben ingevuld.

\section{De fysieke omgeving}

De meerderheid van de werknemers (74\%) gaf aan dat de omgeving van het oude gebouw uitnodigend was om te gaan wandelen, wat in sterk contrast staat met de $27 \%$ van de werknemers die positief was over de omgeving van het nieuwe bedrijfspand. Verder werd de aanwezigheid van winkels, de vele gebouwen/stadse omgeving en de aanwezigheid van wandelpaden en parken bij het oude 
Tabel 1 Achtergrondkenmerken van de onderzoekspopulatie $(n=158)$

\begin{tabular}{ll}
\hline Achtergrondkenmerken & 48 \\
\hline Geslacht (\% vrouw) & 39 (10) \\
Gemiddelde leeftijd (jaren, (SD)) & 57 \\
Opleiding (\% hoger beroepsonderwijs of universiteit) & 76 \\
Werktijden $(\% \geq 36$ uur) & 86 \\
Werkdagen $(\% \geq 4$ dagen per week) & 8 \\
Chronische ziekte (\%) & 80 \\
Algemene gezondheid (\% (zeer) goed) & 49 \\
Beweeggedrag (\% voldoen aan beweegnorm*) & \\
\hline
\end{tabular}

* Op minimaal 5 dagen per week minstens een half uur minimaal matig intensieve lichamelijke activiteit of minimaal 20 minuten intensieve lichamelijke activiteit op tenminste 3 dagen per week

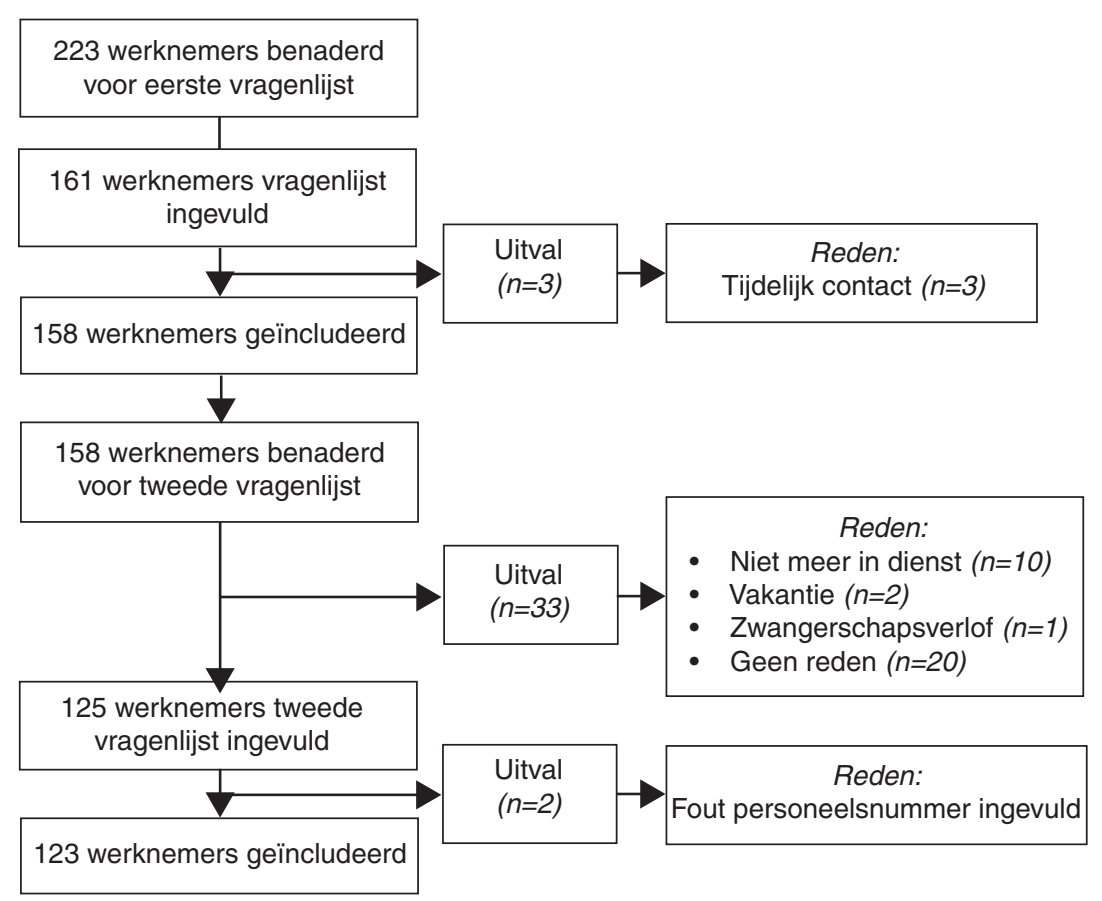

Figuur 1 Gemiddelde lunchwandelfrequentie tijdens het onderzoeksjaar

gebouw door veel van de werknemers positiever beoordeeld dan in de nieuwe situatie. Voor de verhuizing was $13 \%$ van de werknemers tevreden met de kantine, bij de nameting steeg dit percentage naar $98 \%$. De gemiddelde frequentie waarmee werknemers in het nieuwe restaurant kwamen lunchen was 3 (SD 2,1) keer per week. Slechts een klein aantal werknemers (11\%) combineerde het eten in het restaurant met lunchwandelen. Bijna niemand (5\% van de werknemers) nam producten die in het bedrijfsrestaurant gekocht waren mee om tijdens het wandelen te gebruiken.

\section{Lunchpauze}

Bij de voormeting nam 94\% van de werknemers $(n=123)$ tenminste één keer per week een lunchpauze en $83 \%$ nam tenminste vier keer per week een lunchpauze. De gemiddelde frequentie was 4,3 keer per week (SD 1,4) en de gemiddelde duur van de lunchpauze was 32,1 minuten $(\mathrm{SD} 8,2) \mathrm{Bij}$ de nameting bleef de gemiddelde frequentie hetzelfde, maar de gemiddelde duur van een pauze daalde significant naar 29,6 minuten (SD 7,3, p<0,001). Ook waren er significante veranderingen te zien in de activiteiten tijdens de lunchpauze. In het oude gebouw at slechts $8 \%$ van de werknemers de lunch in de kantine, in het nieuwe gebouw steeg dit naar $74 \%$. Bij de voormeting ging $63 \%$ van de werknemers winkelen in de lunchpauze, bij de nameting daalde dit naar $23 \%$. Ook aten bij de nameting minder werknemers hun lunch op achter het bureau, surften minder werknemers op het internet en werd er minder gelezen tijdens de lunchpauze.

\section{Lunchwandelgedrag}

Bij de voormeting wandelde $64 \%$ van de werknemers minimaal één keer per week tijdens de lunchpauze en $49 \%$ wandelde vier of meer keer per week. Bij de nameting daalden beide percentages significant $(\mathrm{p}<0,001)$ naar respectievelijk $31 \%$ en $9 \%$. Van de werknemers die minimaal één keer per week wandelden bij de aanvang van de studie wandelde $57 \%$ een jaar later niet meer.

Bij de voormeting kwam uit de vragenlijst een gemiddelde frequentie van lunchwandelen van 2,6 keer per week (SD 2,1). Dit daalde bij de nameting significant $(\mathrm{p}<0,001)$ naar 0.9 (SD 1,5) keer per week (figuur 2). Bij de vragen per e-mail bleek dat de gemiddelde lunchwandelfrequentie voor de verhuizing 2,2 keer per week (SD 0,1) was. Na de verhuizing daalde deze frequentie significant $(\mathrm{p}<0,001)$ 
naar 0,7 (SD 0,1) keer per week. Er was geen verandering te zien in de duur van de lunchwandelingen: iets meer dan $40 \%$ wandelde $10-20$ minuten, nog eens $40 \%$ wandelde 20-30 minuten, 3\% wandelde 30-40 minuten en de overigen wandelden minder dan 10 minuten.

De meest genoemde reden voor lunchwandelen was 'je bent er even uit' (92\%). Dit werd gevolgd door 'je kunt snel even een boodschap doen' (73\%) en 'het is gezellig' (55\%). Opvallend was de significante daling in mensen die 'om lunch te halen bij bijvoorbeeld de supermarkt of de bakker' (van $41 \%$ naar 9\%, $\mathrm{p}<0,001$ ) of 'je kunt even een boodschap doen' (van $73 \%$ naar $44 \%, \mathrm{p}<0,05$ ) als reden gaven.

In tabel 2 worden de meest genoemde redenen om niet te gaan lunchwandelen weergegeven. In tabel 3 staan de meest genoemde stimulerende omstandigheden om te gaan lunchwandelen. Van de respondenten die minimaal één keer per week wandelden bij aanvang van de studie gaf $82 \%$ aan door de komst van het bedrijfsrestaurant en $77 \%$ door de veranderde omgeving na de verhuizing minder vaak te zijn gaan wandelen. In totaal gaf $73 \%$ aan dat beide factoren (bedrijfsrestaurant en omgeving) ertoe geleid hebben dat ze minder zijn gaan wandelen. Opvallend was dat $60 \%$ van de werknemers, die bij de voormeting aangaf dat er geen omstandigheden waren die hen konden stimuleren om (nog meer) te gaan lunchwandelen omdat zij hoe dan ook wel zouden wandelen, bij de nameting aangaf niet meer te wandelen.

\section{DISCUSSIE}

Tijdens de voormeting wandelde $64 \%$ van de werknemers tenminste één keer per week tijdens de lunch, wat aanzienlijk hoger is dan de $20-30 \%$ die gerapporteerd werd in een landelijke enquête naar lunchwandelgedrag. ${ }^{1,12}$ Direct na de verhuizing van het bedrijf was een significante daling te zien in zowel het aantal als de frequentie van de lunchwandelingen. Bij de nameting wandelde 31\% van de werknemers minimaal één keer per week, wat beter overeen komt met de resultaten van de eerder genoemde landelijke enquête. Er is geen significante verandering gevonden in de gemiddelde duur van de lunchwandelingen. Blijkbaar heeft de veranderde omgeving bij de mensen die wel zijn blijven lunchwandelen geen invloed gehad op de duur van de wandelingen.

Bij aanvang van het onderzoek leek het lunchwandelen onderdeel te zijn van de bedrijfs'cultuur', want er werd door veel werknemers gewandeld tijdens de lunch. Na de verhuizing werd er echter beduidend minder gewandeld. Omgevingsfactoren kunnen dus voor een groot deel het lunchwandelgedrag van de werknemers bepalen. Vermoedelijk waren het vooral de praktische omstandigheden (het gebrek aan een fatsoenlijk bedrijfsrestaurant en/ of veel aantrekkelijke winkels in de buurt) die ertoe leidden dat er veel gewandeld werd tijdens de lunch. Dit wordt bevestigd door de resultaten van de nameting. Veel vaker dan tijdens de voormeting wordt bij de nameting

Tabel 2 Meest genoemde redenen om niet te gaan lunchwandelen, bij voormeting en nameting $(n=115)$

\begin{tabular}{|c|c|c|c|}
\hline Redenen (\%) ** & voormeting & nameting & $p$ (McNemar Test) \\
\hline Tijdgebrek & 46 & 47 & 1,00 \\
\hline Mijn werkzaamheden laten het niet toe & 34 & 14 & $<0,001$ \\
\hline Het weer laat het vaak niet toe & 25 & 17 & 0,10 \\
\hline Andere redenen & 26 & 13 & $<0,05$ \\
\hline Geen zin in & 10 & 23 & $<0,05$ \\
\hline Ik zou wel willen, maar het komt er gewoon niet van & 9 & 12 & 0,523 \\
\hline Ik ga graag lunchen in de kantine/het restaurant & 4 & 44 & $<0,001$ \\
\hline Ik beweeg meer dan genoeg op mijn werk & 3 & 3 & 1,00 \\
\hline De omgeving van het bedrijf is niet aantrekkelijk & 1 & 18 & $<0,001$ \\
\hline
\end{tabular}

** 12 antwoordmogelijkheden

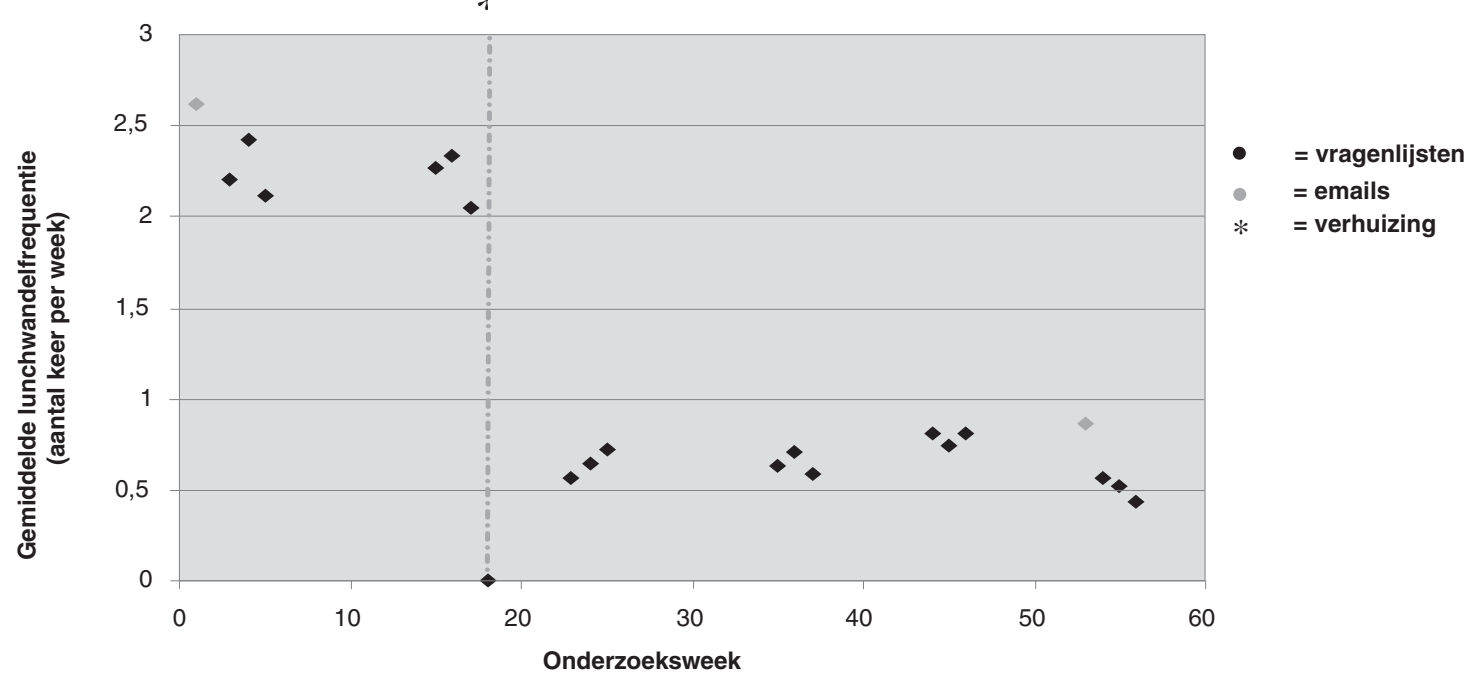

Figuur 2 Gemiddelde lunchwandelfrequentie tijdens het onderzoeksjaar 
aangegeven dat men niet ging lunchwandelen omdat men graag in het restaurant ging lunchen. De voornaamste reden om te gaan lunchwandelen was zowel bij de voormeting als de nameting 'je bent er even uit'. Vergelijkbare resultaten werden gevonden in een eerdere interventiestudie naar lunchwandelen. ${ }^{11}$ De significante daling in het aantal werknemers die lunchwandelen doet echter twijfelen of dit daadwerkelijk de voornaamste reden was, omdat de verhuizing op deze reden geen directe invloed heeft. Blijkbaar is de reden 'je bent er even uit' ondergeschikt aan de aanwezigheid van een aantrekkelijke omgeving of een fatsoenlijk bedrijfsrestaurant. Ook de significante daling in het percentage werknemers die aangaven te gaan lunchwandelen 'om lunch te halen bij bijvoorbeeld de supermarkt of de bakker' of om de reden 'je kunt even snel een boodschap doen' duidt erop dat de verandering in fysieke omgeving door de verhuizing een belangrijke oorzaak is van de verminderde deelname aan lunchwandelen. De groep werknemers die echter ook na de verhuizing bleef lunchwandelen gaf naast de reden 'je bent er even uit' ook vaak aan te gaan lunchwandelen omdat ze het gezellig vinden en omdat het gezond is. In deze groep blijvende lunchwandelaars spelen deze 'intrinsieke' redenen dus ook een belangrijke rol.

Deze studie kent een aantal beperkingen. Ten eerste gaven de respondenten bij de nameting aan dat ze de aanwezigheid van winkels op de nieuwe locatie misten en ze vonden de omgeving na de verhuizing minder aantrekkelijk. Tegelijkertijd kan ook de aanwezigheid van het bedrijfsrestaurant in het nieuwe gebouw de afname in het lunchwandelen veroorzaakt hebben. Bijna alle respondenten gaven aan zeer tevreden te zijn met het restaurant en ze gaven aan hier ook zeer vaak te lunchen. Het is echter in deze studie niet mogelijk om te bepalen welke omgevingsfactor de grootste invloed heeft op het lunchwandelgedrag, omdat beide omgevingsfactoren tegelijkertijd zijn veranderd. Ook zijn er tot op heden geen andere studies gedaan naar de invloed van een veranderde omgeving op het lunchwandelgedrag, waardoor uitspraken hierover niet mogelijk zijn. Waarschijnlijk zijn beide omgevingsfactoren van even groot belang voor de mate van lunchwandelen, aangezien de meerderheid van de respondenten aangaf minder te zijn gaan lunchwandelen door zowel de komst van het restaurant als de veranderde bedrijfsomgeving.

Ten tweede was het begrip lunchwandelen niet duidelijk gedefinieerd. Een gevolg hiervan was dat sommige respondenten winkelen tijdens de lunchpauze als lunchwandelen zagen (dit was een vaak genoemde reden), ter- wijl anderen alleen een wandeling van langere duur en/of hoger tempo als lunchwandelen zagen. De eerstgenoemde groep was redelijk groot, want het aantal werknemers dat als reden opgaf 'om een lunch te halen bij bijvoorbeeld de supermarkt of de bakker' of 'je kunt even een boodschap doen' was relatief hoog bij de voormeting en daalde significant na de verhuizing. De voormeting zal dus waarschijnlijk een overschatting zijn geweest van het lunchwandelgedrag. De werknemers die ook na de verhuizing zijn blijven wandelen zijn in mindere mate 'winkelaars' en kunnen meer bestempeld worden als 'echte wandelaars'. Het wandeltempo zal bij de laatste groep waarschijnlijk ook hoger liggen dan bij de winkelaars. Gezien het feit dat de meeste gezondheidsvoordelen ontstaan als er stevig doorgewandeld wordt, ${ }^{5}$ is het zinvol om in toekomstig onderzoek zowel het doel van de wandeling als het wandeltempo expliciet na te vragen. Ook werd het wandelgedrag op twee verschillende manieren nagevraagd; één vraag ging over de activiteiten die regelmatig uitgevoerd werden tijdens lunchtijd, de andere vraag ging over de frequentie van lunchwandelen. Bij de nameting gaf $45 \%$ van de respondenten aan dat 'wandelen' een activiteit was die regelmatig tijdens de lunchpauze gedaan werd. Opvallend was echter dat 34\% van deze werknemers aangaf dat de frequentie van het lunchwandelen ' 0 keer per week' was. Blijkbaar werd de term 'regelmatig' door de werknemers verschillend geïnterpreteerd: sommigen denken daarbij mogelijk aan tenminste twee keer per week, terwijl anderen dit bijvoorbeeld als tenminste twee keer per maand hebben gezien. Een duidelijke definitie van 'regelmatig' zou verwarring bij het beantwoorden van deze vragen kunnen voorkomen.

Tot slot lieten de beide vragenlijsten een iets hogere frequentie van lunchwandelen zien dan de frequenties gerapporteerd in de e-mails. Een verklaring hiervoor zou kunnen zijn dat in de e-mails gevraagd werd naar het lunchwandelgedrag van de afgelopen week, terwijl er in de vragenlijsten geen specifieke periode genoemd werd. Het lijkt erop dat respondenten hun frequentie van lunchwandelen overschatten wanneer er in algemene zin, dus niet over een specifieke periode, naar wordt gevraagd. Om beter inzicht te krijgen in het daadwerkelijke wandelgedrag is het daarom aan te bevelen naast zelfrapportage meer objectieve meetinstrumenten te gebruiken, zoals stappentellers.

\section{CONCLUSIE EN AANBEVELINGEN}

Zowel de omgeving van het bedrijf als het bedrijfsrestaurant lijken een sterke invloed te hebben op het

Tabel 3 Meest genoemde stimulerende omstandigheden voor lunchwandelen, bij voormeting en nameting ( $n=115$ )

\begin{tabular}{|c|c|c|c|}
\hline Stimulerende omstandigheden (\%)* & voormeting & nameting & $p$ (McNemar Test) \\
\hline Geen, ik ga hoe dan ook wandelen & 44 & $-a^{a}$ & - \\
\hline Meer winkels in de omgeving & 22 & 50 & $<0,001$ \\
\hline Een park in de omgeving & 19 & 19 & 1,00 \\
\hline Geen, ik zal hoe dan ook niet gaan wandelen tijdens de lunchpauze & 15 & 25 & $<0,05$ \\
\hline Andere redenen & 10 & 13 & 0,50 \\
\hline Meer wandelpaden of wandelroutes in de omgeving & 8 & 12 & 0,33 \\
\hline Collega's om samen mee te wandelen & 6 & 13 & 0,10 \\
\hline
\end{tabular}

${ }^{a}$ Het was niet mogelijk dit antwoord te kiezen in de nameting

* 10 antwoordmogelijkheden 
lunchwandelgedrag van werknemers. Bedrijven met een minder aantrekkelijke omgeving en een modern bedrijfsrestaurant zullen daarom een overtuigendere aanpak nodig hebben om hun werknemers te stimuleren om te gaan lunchwandelen dan bedrijven die een prettige wandelomgeving hebben en/of niet over een modern restaurant beschikken. Om werknemers in een minder gunstige omgeving toch te stimuleren om te gaan lunchwandelen zou het bedrijfsrestaurant aantrekkelijke lunchpakketjes (om mee te nemen) aan de medewerkers kunnen aanbieden, waardoor men niet afhankelijk is van een bakker in de buurt. Daarnaast zouden er wandelroutes van 20 of 30 minuten uitgezet kunnen worden langs leuke plekken (die de medewerkers vaak nog niet kennen) in de buurt van het bedrijf. Tenslotte zouden enthousiaste medewerkers, die op verschillende afdelingen in het gebouw werkzaam zijn, aangewezen kunnen worden als 'aanjager', met als opdracht hun collega's frequent mee naar buiten te nemen om te gaan lunchwandelen.

\section{DAN KWOORD}

Deze studie is gefinancierd door het ministerie van VWS. De auteurs bedanken het marktonderzoeksbureau en hun werknemers voor de deelname aan het onderzoek.

\section{ABSTRACT}

Influence of the environment on walking behavior during lunch break

Objectives: A Dutch company moved from a building without a decent company restaurant and a pleasant walking environment to a new building with a modern company restaurant and a less appealing walking environment. The aim of this study was to investigate the effect of the changed working environment on walking behavior during lunch break. Methods: Information on walking behavior and factors hindering participants from walking during lunch break were collected by online questionnaires at baseline (eighteen weeks before the moving) and one-year follow-up and by regular e-mails during the study year. Results: 123 participants ( $55 \%$ of the eligible employees) completed both questionnaires. At baseline $64 \%$ walked at least once a week and $49 \%$ walked at least four times a week during lunch break. At follow-up these percentages decreased significantly to $31 \%$ and $9 \%$, respectively. The duration of a walk during lunch break had not changed significantly. $73 \%$ of the participants reported that the company's restaurant as well as the changed company's environment had influenced them to walk less. Conclusions: The amount of employees walking during lunch break decreased drastically after removal. The results suggest that both the presence of a company restaurant and the attractiveness of the neighborhood of the company building strongly influence the walking behavior of employees during lunch break. Keywords: physical environment; physical activity; company restaurant; work site.

\section{LITERATUUR}

1. US Department of Health and Human Services. Physical activity and health: A report of the Surgeon General. Atlanta: US
Department of Health and Human Services, Centers for Disease Control and Prevention, 1996.

2. Kesaniemi $Y K$, Danforth E, Jensen MD, Kopelman PG, Lefebvre $P$, Reeder BA. Dose-response issues concerning physical activity and health: An evidence-based symposium. Med Sci Sports Exerc 2001;33:351-8.

3. Durán OHF. Cardiovascular Disease Prevention. Enschede: PrintPartners Ipskamp, 2005.

4. Hildebrandt VH, Ooijendijk WTM, Hopman-Rock M (red). Trendrapport Bewegen en Gezondheid 2006/2007. Leiden: TNO Kwaliteit van Leven, 2008.

5. Haskell WL, Lee IM, Pate RR et al. Physical activity and public health: updated recommendation for adults from the American College of Sports Medicine and the American Heart Association. Med Sci Sports Exerc 2007;39:1423-34.

6. Salmon J, Owen N, Bauman A, Schmitz MK, Booth M. Leisuretime, occupational, and household physical activity among professional, skilled, and less-skilled workers and homemakers. Prev Med 2000;30:191-9.

7. Pereira MA, Kriska AM, Collins VR et al. Occupational status and cardiovascular disease risk factors in the rapidly developing, high-risk population of Mauritius. Am J Epidemiol 1998; 148:148-59.

8. Ball K, Timperio A, Salmon J, Giles-Corti B, Roberts $R$, Crawford $D$. Personal, social and environmental determinants of educational inequalities in walking: a multilevel study. J Epidemiol Commun Health 2007;61:108-14.

9. Humpel $N$, Owen $N$, Iverson D, Leslie E, Bauman A. Perceived environment attributes, residential location, and walking for particular purposes. Am J Prev Med 2004;26:119-25.

10. Burgoyne L, Coleman R, Perry IJ. Walking in a city neighborhood, paving the way. J Public Health (Oxf) 2007;29:222-9.

11. Hendriksen IJM, Hildebrandt VH. Lunchwandelen? Lunchwandelen! Resultaten van een landelijke enquête onder werknemers en management. TNO-rapport R0314106/018-44263. Leiden: TNO Kwaliteit van leven, 2003.

12. Kraker $H$ de, Hendriksen IJM, Hildebrandt VH, Korte EM de, Maas EMM van der. Het effect van een lunchwandelcampagne op het beweeggedrag van werknemers. Geneeskunde en Sport 2005;38:172-8.

13. Humpel N, Owen N, Leslie E. Environmental factors associated with adults' participation in physical activity: a review. Am J Prev Med 2002;22:188-99.

14. Ball K, Bauman A, Leslie E, Owen N. Perceived environmental aesthetics and convenience and company are associated with walking for exercise among Australian adults. Prev Med 2001; 33:434-40.

15. Owen N, Humpel N, Leslie E, Bauman A, Sallis JF. Understanding environmental influences on walking; Review and research agenda. Am J Prev Med 2004;27:67-76.

16. Brug J, Lenthe F van (red). Environmental determinants and interventions for physical activity, nutrition and smoking. Zoetermeer: Speed-print, 2005:108-67.

\section{CORRESPONDENTIEADRES}

Dr I.J.M. Hendriksen, TNO Kwaliteit van leven, Postbus 2215, 2301 CE Leiden, tel.:071 - 5181885, e-mail: ingrid.hendriksen@tno.nl

Voor publicatie aanvaard in januari 2009. 